\title{
Abnormal intragastric distribution of food during gastric emptying in functional dyspepsia patients
}

\author{
L E A Troncon, R J M Bennett, N K Ahluwalia, D G Thompson
}

\begin{abstract}
Although delayed gastric empyting is found in some patients with functional dyspepsia, there seems to be little relation between rate of emptying and symptoms. This study examined the hypothesis that food maldistribution rather than gastric stasis may equate to symptoms in such patients and used scintigraphic techniques to quantify the partition of gastric contents between proximal and distal stomach during gastric emptying. Eleven patients with functional dyspepsia characterised by chronic severe postprandial bloating without organic abnormality, and 12 healthy volunteers, ingested a standard meal labelled with technetium-99M $\left.{ }^{99 m} \mathrm{Tc}\right)$. Serial images of the gastric area in anterior and posterior projections were taken for 90 minutes, regions of interest for proximal, distal, and total stomach were defined, and activity time curves were derived from the geometric means of anterior and posterior counts. Total emptying in patients (median: 46 minutes; range: $30-76$ ) was not significantly different from controls (45 minutes; 28-58) and only three showed delayed gastric emptying. In controls, food remained predominantly in the proximal half of the stomach after ingestion and then redistributed to the distal half. In the patients, however, initial activity in the proximal half after ingestion $(48 \% ; 40-65)$ was significantly lower $(\mathbf{p}<0.05)$ than in controls $(60 \% ; 39-73)$ and distributed more fully to the distal half of the stomach with a peak distal activity $(56 \% ; 34$ 58), which was consistently higher than in controls $(36 \% ; 33-42)(p<0.05)$. It is concluded that this subgroup of functional dyspepsia patients show abnormal intragastric distribution of food, independent of gastric emptying rate.

(Gut 1994; 35: 327-332)
\end{abstract}

Functional dyspepsia is a common condition defined by a variety of upper abdominal symptoms, which are not explained by any demonstrable organic abnormality. ${ }^{1}$ Symptoms include upper abdominal discomfort or pain, epigastric bloating or fullness, early satiety, nausea and vomiting, which often occur in clusters and are commonly caused or aggravated by food ingestion. ${ }^{2}$

Delayed gastric emptying for solids or liquids, or both has been repeatedly reported in a substantial proportion of patients with functional dyspepsia, ${ }^{3-6}$ and in some studies, gastroparesis has been associated with abnormalities of gastric myoelectric activity ${ }^{7}$ and antral motility. ${ }^{6}$ Probably, however, these motor abnormalities can not fully explain the pathophysiology of all patients with functional dyspepsia, because gastric stasis correlates poorly with symptoms9 and gastric emptying and motility can be normal in some patients despite identical symptoms.

Gastric emptying is determined by the coordinated function of at least two physiologically distinct compartments of the stomach. The proximal stomach accommodates food and regulates its transfer to the distal compartment, which seems to take part in grinding and mixing intragastric contents as well as participating in the regulation of nutrient delivery to the duodedum. ${ }^{10}$

The distribution of nutrients within these two regions of the stomach have recently been studied in humans using an isotopic technique $^{11-15}$ to study the partitioning of an ingested test meal between a proximal and distal gastric region of interest. It has now been established that nutrients are located predominantly in the proximal stomach after ingestion with progressive distribution into the distal stomach as emptying progresses. This proximal gastric reception of ingested nutrients is consistent with animal findings that gastric fundal tone is reduced by food. So far, however, nutrient distribution in dyspeptic patients has not been explored.

We examined the hypothesis that the bloating sensation experienced by some patients during and after meal ingestion could be a result of impaired proximal gastric accommodation and therefore studied intragastric nutrient distribution in a group of dyspeptic patients. Our results suggest that nutrient distribution is indeed abnormal and that meal retention in the proximal stomach is decreased.

\section{Subjects and methods}

SUBJECTS

\section{Patients}

Eleven patients with functional dyspepsia ( 5 male and 6 female, median age: 45 years, range $20-60$ ) and 12 healthy asymptomatic volunteers ( 7 male and 5 female, median age: 34 years, range: 22-46) participated in the study after giving informed consent. The protocol for the study had been previously approved by the Salford Health Authority ethics committee.

All functional dyspepsia patients were specifically selected to fall within the clinical subgroup of 'dysmotility type' dyspeptics.' All had experienced similar symptoms comprising severe upper abdominal discomfort and bloating related to meals, for at least one year and all were symptomatic at the time of the study. None had a history of peptic ulcer like symptoms or previous
Correspondence to: Dr D G Thompson, University Department of Medicine, Clinical Sciences Building, Road, Salford M6 8HD.

Accepted for publication 7 July 1993
LE A Troncon University of Mancheste Medical School, Hope 
gastroduodenal surgery, and none had evidence of any systemic disease known to affect gastrointestinal motility. Symptom character, severity, and chronicity was also similar in both sexes. Common laboratory tests, upper digestive tract endoscopy, barium meal, and abdominal ultrasonography were normal in all patients. All drugs were stopped for at least 72 hours before the study.

\section{Healthy volunteers}

The control group comprised a group of healthy adult volunteers, with no past history of gastrointestinal disease or previous abdominal surgery, who were selected from medical personnel and the student population of Hope Hospital.

TEST MEAL

All subjects were studied using the same test meal, which comprised $415 \mathrm{ml}(425 \mathrm{~g})$ of a commercially available semi liquid soup (cream of chicken soup, $\mathrm{H} \mathrm{J}$ Heinz Ltd) to which $12 \mathrm{MBq}$ of technetium-99M $\left({ }^{99 \mathrm{~m}} \mathrm{Tc}\right)$ pertechnetate was added. The nutrient composition of the meal was, $204 \mathrm{kcal}, 12 \mathrm{~g}$ fat, $6 \mathrm{~g}$ protein, $19 \mathrm{~g}$ carbohydrate.

Laboratory bench studies with the meal showed that it was highly stable with no evidence of physical separation when left for up to 12 hours. Studies of the distribution of the isotope within the meal also showed that it remained homogeneously distributed.

\section{STUDY PROTOCOL}

Gastric emptying and intragastric distribution of a radiolabelled nutrient meal were assessed by external abdominal scintigraphy. After an over- night fast of at least 10 hours, subjects ingested the test meal, which had been warmed to $40^{\circ} \mathrm{C}$.

Immediately after meal ingestion, images of the radioactivity in the abdomen were collected by standing the subjects in front of the low energy, high sensitivity collimator of a gammacamera (Ohio Nuclear, series 100 , Solon, Ohio, USA) connected to an image processing system.

Images of both the anterior and posterior views of the abdomen were taken for one minute each at $5,10,15,20,30,40,50,60,75$, and 90 minutes after beginning ingestion of the meal. In the intervals between image acquisition they sat comfortably in a chair near the camera. The gammacamera was set up to record activity with a $20 \%$ window around the $140 \mathrm{KeV}$ photopeak of ${ }^{99 \mathrm{~m}} \mathrm{Tc}$. All images were stored on magnetic tape for analysis after completion of the study.

\section{DATA ANALYSIS}

The overall area of the gastric region of interest was first established by counting the number of isotope containing pixels enclosed within the initial gastric image (Fig 1). This gastric region of interest was then divided into two equal areas, designated the proximal and distal stomach, by using the cursor facility of the machine to place a line across the stomach so that $50 \%$ of the isotope containing pixels were present in each area, irrespective of the number of isotope counts in each pixel. To avoid possible bias, the construction of the two regions of interest was performed by an observer who was unaware of the subject's allocation into either the control or the functional dyspepsia group.

The total counts in the three regions of interest (total stomach, proximal stomach, and distal stomach) was then determined for all 20 images. Counts were corrected for radioactive decay and
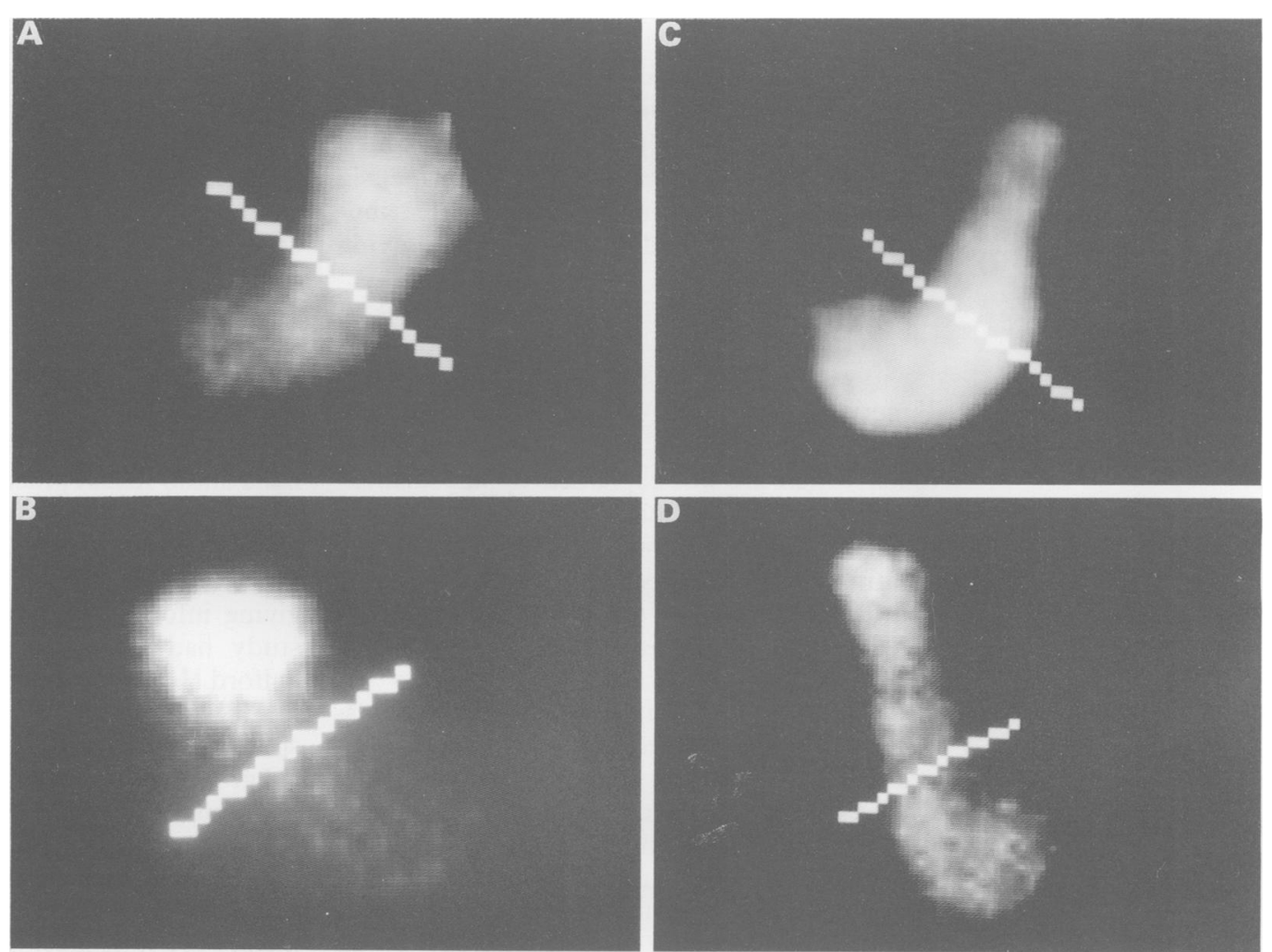

Figure 1: Representative gammacamera images taken immediately after meal

ingestion, are shown. Images $A$ and $B$ are anterior and posterior views taken from a normal volunteer while images $C$ and $D$ are anterio and posterior views from $a$ dyspeptic patient. Each image shows a line dividing the gastric area of interest into proximal and distal halves.

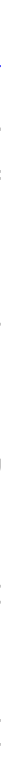




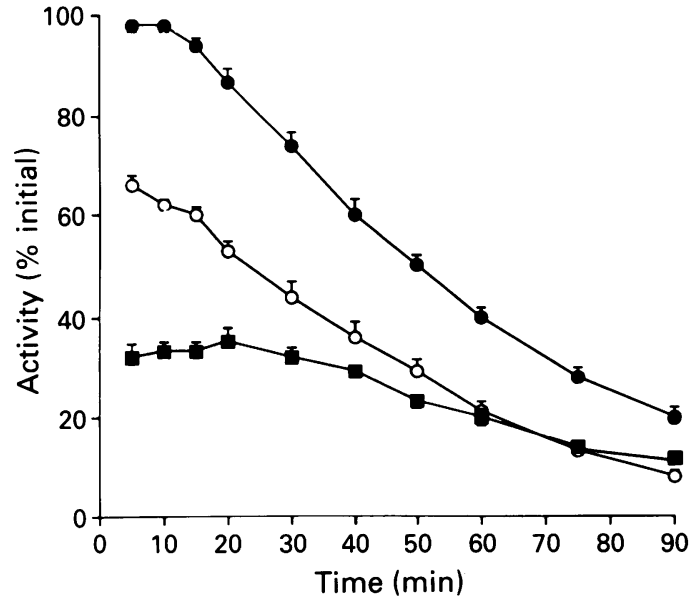

Figure 2: This figure shows total gastric emptying (closed circles) and intragastric distribution of ingested radioactivity between proximal (open circles) and distal (squares) stomach in 12.control subjects. Data points show group mean (SEM).

room background. In addition, to correct for the effect of anterior-posterior movement of the radio activity, a geometric mean of the anterior and posterior counts for each region was calculated at each time point. ${ }^{16}$ The initial activity (IA), when theoretically all the ingested radioactivity was contained in the stomach, was obtained by extrapolation from the corrected counts at the first two time points - (that is, at five minutes and 10 minutes after meal ingestion). The activity in each region at any time point during the study was expressed as a percentage of IA. Activity $v$ time curves were produced for each of the three regions.

\section{GASTRIC EMPTYING}

Gastric emptying was assessed by calculating the following parameters from the activity $v$ time curve for the total stomach: (a) gastric emptying $\left(\mathrm{T}^{1} / 2\right)$ : the time (min) taken for the IA to fall by $50 \%$; (b) gastric retention at 30 minutes: the percentage of the IA found at 30 minutes. This was used as an index of the earlier phase of gastric emptying; (c) gastric retention at 90 minutes: the percentage of the IA found at 90 minutes. This was used as an index of the later phase of gastric emptying; (d) total gastric residence: the area under the activity $v$ time curve.

\section{INTRAGASTRIC DISTRIBUTION}

The distribution of radioactivity between the proximal and the distal stomach was assessed by calculating the following parameters from the activity $v$ time curves derived from each region: (e) initial proximal activity: the percentage of IA contained in the proximal stomach immediately after the end of meal ingestion; ( $f$ ) maximal distal content: the highest activity value in the distal stomach at any time point in the study'

Total gastric emptying parameters

\begin{tabular}{lccc}
\hline Parameter & Controls & Functional dyspepsia & p Value \\
\hline T $1 / 2(\min )$ & $45(28-58)$ & $46(30-76)$ & $>0 \cdot 10$ \\
Retention at $30 \min (\%)$ & $68(43-92)$ & $68(58-86)$ & $>0 \cdot 10$ \\
Retention at $90 \min (\%)$ & $17(7-28)$ & $28(12-42)$ & $>0 \cdot 10$ \\
Total gastric residence $(\min )$ & $4422(4162-4932)$ & $4450(3960-5467)$ & $>0 \cdot 05$ \\
\hline
\end{tabular}

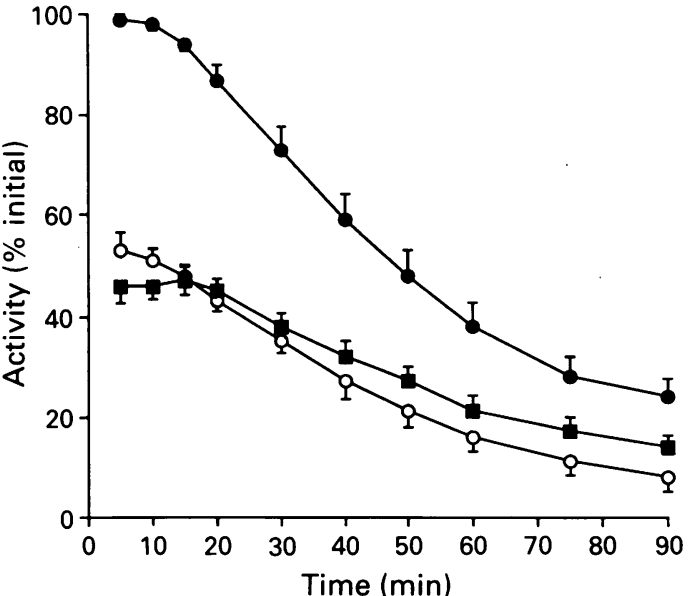

Figure 3: Gastric emptying and intragastric distribution of ingested radioactivity between proximal and distal stomach in the 11 patients with functional dyspepsia (symbols as Figure 2). Data points show group mean (SEM).

(g) distal gastric residence: the area under the activity $v$ time curve derived from the distal stomach, expressed as percentage of total gastric residence.

The areas under the activity $v$ time curves were calculated by computing the cumulative sum of the products of the means of successive activity values multiplied by the time interval between them.

\section{STATISTICAL ANALYSIS}

Because preliminary inspection of the data suggested that a normal distribution could not be assumed, results are expressed in the text as median and range, and non-parametric methods were used for the statistical analysis. ${ }^{17}$ The differences between functional dyspepsia patients and controls were analysed by the Mann-Whitney U test. Differences were taken as being biologically relevant when values of $p$ were less than $0 \cdot 05$.

\section{Results}

\section{GASTRIC EMPTYING}

The activity $v$ time curve for the total stomach in the control group was characterised by a roughly linear decline of activity with time (Fig 2). In the functional dyspepsia group a similar pattern was seen (Fig 3) and no consistent differences were found between the two groups for any of the gastric emptying parameters (Table). In three of 11 patients, however, the individual values for $T^{1} 1 / 2(59,64$, and 76 minutes) were greater than the highest value seen in controls, showing that their gastric emptying was abnormally delayed.

\section{INTRAGASTRIC DISTRIBUTION OF FOOD}

\section{Normal volunteers}

Partitioning of ingested radioactivity between the proximal and the distal stomach (Fig 2) occurred immediately after meal ingestion, most of the activity residing in the proximal stomach (initial proximal activity: $60 \% ; 39$ to 73 ). In the first 20 minutes after meal ingestion, however, 
Figure 4: Individual values for maximal distal content in control subjects $(C)$ and in patients with functional dyspepsia $(F D)$. Horizontal bars represent the respective medians.

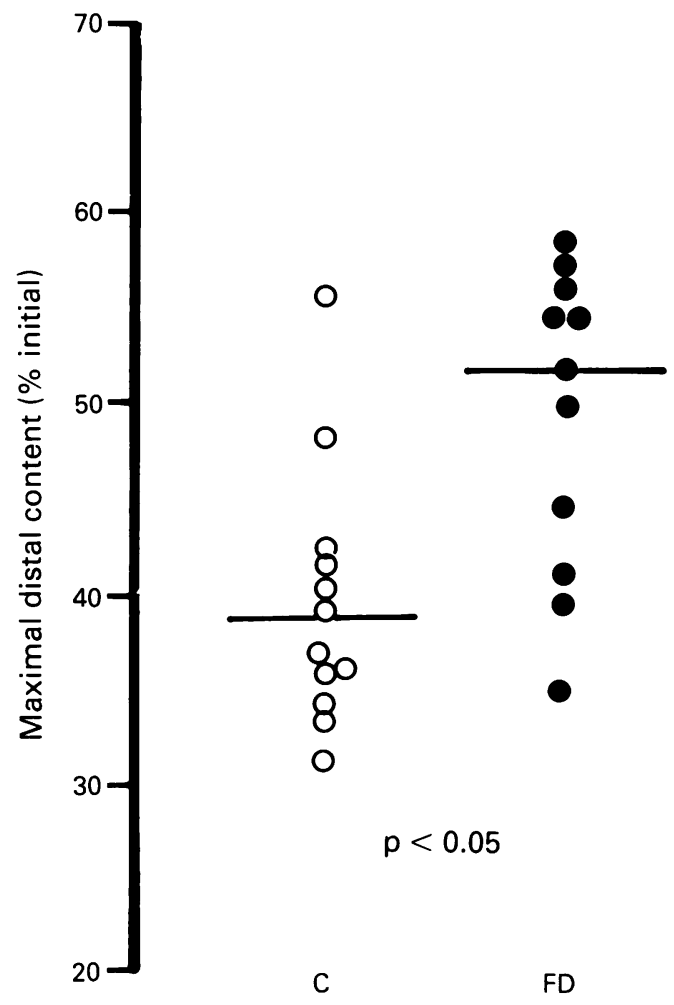

activity in the proximal stomach decreased, with a corresponding increase in activity in the distal stomach, pointing to a redistribution of food from the proximal to the distal stomach. In the later stages of emptying, activity decreased at an equal rate in both regions.

\section{Dyspeptic patients}

In the dyspeptic patients, (Fig 3) the initial proximal activity $(48 \% ; 40$ to 65$)$ was lower than in the controls $(\mathrm{p}<0.05)$.

Values for maximal distal content (Fig 4) for the dyspeptic patients $(56 \% ; 34$ to 58$)$ were higher than in controls $(36 \% ; 33$ to 42$)(p<0.02)$. Furthermore, the percentage distal gastric resid-

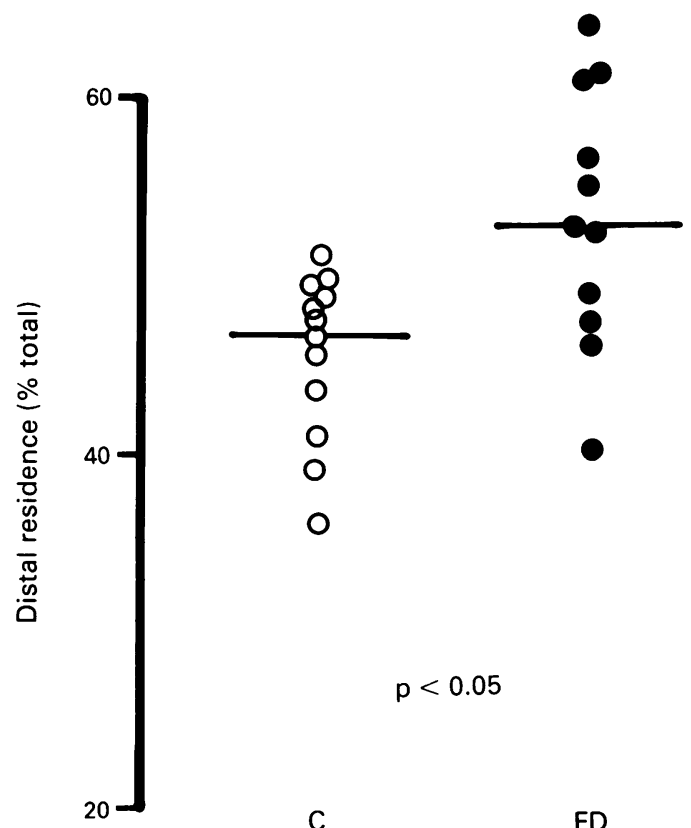

ence in dyspeptic patients $(32 \cdot 5 \% ; 38 \cdot 7-61 \cdot 7)$ was higher than in the control group $(44.3 \%$; $36.5-50.3)(p<0.05)$, showing that a larger proportion of the ingested activity was contained in the distal stomach throughout gastric emptying (Fig 5).

No consistent relation was found between sex and any measure of isotope distribution $(p>0.05)$ or between gastric emptying rate and distal gastric residence. Those patients whose $t / 2$ was slower than the control range had similar values for distal residence $(55 \%, 43-62)$ to those with normal $t / 2$ values $(52 \%, 39-60)(p>0 \cdot 2)$.

\section{Discussion}

It is now widely accepted that functional dyspepsia constitutes a heterogenous group of conditions with diverse underlying pathophysiologic disturbances. ${ }^{2}$ In an attempt to increase homogeneity of the population sample under investigation, we included in our work only dysmotility type dyspeptic patients, patients with chronic, severe postprandial bloating as the major symptom, because this is generally taken to suggest that a disturbance of gastric motility might be present. ${ }^{1}$ In this selected group of dyspeptic patients we tested the hypothesis that food distribution into the proximal stomach would be abnormal and found consistent differences between them and normal volunteers, which may be pathophysiologically relevant.

Despite reports describing the definition of proximal and distal regions of interest by visual means, ${ }^{13-15}$ we found in practice that it was difficult to define a proximal reservoir separated from the more distal stomach, by inspecting our scans. While some subjects showed a 'waist' between what seemed to be proximal stomach and antrum, this was not a consistent finding and so division of the stomach by this method was not attempted. We therefore defined the region of interest for the proximal stomach as corresponding to the upper half of the total gastric area, as this has had the advantage of reproducibility while still being compatible with the roughly 60:40 proximal:distal separation described by others. ${ }^{13-15}$ Our 50:50 separation also seems to be compatible with accepted anatomical and psysiological criteria of fundal dimensions. ${ }^{18}$

${ }^{99} \mathrm{~m}$ Tc-pertechetate was originally chosen as the radiopharmaceutical in the expectation that it would label both liquid and solid components of the meal. ${ }^{19}$ That this in fact occurred is suggested by the finding that the gastric emptying curves in both groups showed an intermediate shape between the exponential emptying pattern typical of liquids and the linear emptying after a lag period typical of solids. ${ }^{20}$ No evidence of separation of the meal into fat or aqueous phases was noted either on leaving the meal standing on the laboratory bench for up to 12 hours or on inspection of the images during the emptying studies. Because of the theoretical possibility that some pertechnetate that was unbound to the meal could be absorbed in the stomach wall and affect the analysis we have, more recently, also used meals labelled with ${ }^{90} \mathrm{Tc}^{\mathrm{m}}$-DTPA, which is not absorbed by the
Figure 5: Individual values for distal residence in control subjects $(C)$ and in patients (FD). Horizal dyspepsia represent the respective medians. 
gastric mucosa, and have obtained identical results.

The predominant location of gastric content in the distal stomach in our functional dyspepsia patients seems to be independent of gastric stasis, because only three of 11 of the patients had gastric emptying that was more delayed than our controls. Although it is sometimes assumed that delayed emptying is a frequent finding in dysmotility type dyspeptic patients, ${ }^{3-6}$ other studies have also reported similar variability in emptying data to our own' and it may be that the proportion of patients who show delayed emptying is related to the selection criteria used. ${ }^{10}$ The increased distribution of intragastric contents in the distal stomach is also consistent with the results of ultrasonographic studies showing that dyspepsia patients tend to have larger postprandial antral volumes. ${ }^{21}$

Theoretically, the increased location of ingested food in the distal stomach could either be the result of impaired proximal gastric relaxation or increased distal gastric accommodation. The possibility of defective proximal gastric relaxation in functional dyspepsia has long been suspected $^{2}$ but only recently explored..$^{22-24}$ In contrast with our results, these three studies, each using different methods to induce gastric distension, failed to show any consistent differences between normal subjects and dyspeptic patients in gastric proximal relaxation. It is important to note, however, that all three studies were conducted during fasting, a condition that may be unrepresentative of the pathophysiology in dyspeptic patients who characteristically suffer from postpradial symptoms. In support of our data, defective meal induced reduction in proximal gastric tone has been recently reported in functional dyspepsia patients selected by the same criteria used in this study. ${ }^{25}$

The possibility that antral accommodation may be enhanced in dyspeptic patients has not been investigated. It has been shown, however, that postprandial antral motor activity is impaired in functional dyspepsia ${ }^{6726}$ and it is possible that this could also be associated with an abnormally low antral tone.

Like other visceral organs, the human upper gastrointestinal tract seems to have a limited repertoire of associated sensations, because luminal distension of either the gastric fundus ${ }^{25}$ or the antrum and the duodenum ${ }^{28}$ elicits similar symptoms of epigastric bloating and fullness. In a recent study ${ }^{29}$ using ultrasonography to assess gastric dimensions, it was found that symptom scores for bloating but not for other dyspeptic symptoms were significantly related to the cross sectional area of the antrum. This finding, taken together with the results of our study, suggests that it may be the increased antral distension by ingested food which plays the major part in symptom production.

While it has been suggested that women are more troubled by dyspepsia, ${ }^{30}$ we could not find any sex differences in degree of physiological abnormality in our patients. It is important to note, however, that the number of patients studied is probably too small to allow detection of anything other than the grossest differences. Furthermore, our method of recruitment, which was designed to ensure that patients with similar symptom severity were chosen for study would also have acted to reduce any male:female differences.

In conclusion, we have identified intragastric maldistribution in a group of dyspeptic patients with severe postprandial bloating who show decreased residence of gastric contents in the proximal stomach and increased distribution to the distal stomach. These abnormalities could be explained by defective proximal gastric relaxation, by increased distal gastric accommodation, or by a combination of the two.

Dr Troncon was the recipient of a fellowship grant from a covenant between the University of São Paulo, Brazil and the Interamerican Development Bank.

1 Talley NJ, Colin-Jones D, Koch K, Koch M, Nyren O, Stangellini V. Functional gastrointestinal disorders: guidelines for diagnosis and management. Gastroenterology International 1991; 4: 145-60.

2 Talley NJ, Phillips SF. Non-ulcer dyspepsia: potential causes and pathophysiology. Ann Intern Med 1988; 108: 865-79.

3 Corinaldesi R, Stanghellinin V, Raiti C, Rea E, Salgemini R, Barbara L. Effect of chronic administration of cisapride on gastric emptying of a solid meal and on dyspeptic symptoms in patients with idiopathic gastroparesis. Gut 1987; 28: $300-5$.

4 Jian R, Ducrot F, Ruskone A, Chaussade S, Rambaud JC, Modigliani R, et al. Symptomatic, radionuclide and theraModigliani $\mathrm{R}$, et al. Symptomatic, radionuclide and therapeutic assessment of chronic idiopathic dyspepsia. A doubleblind placebo-con

5 Wegener M, Borsch G, Schaffstein J, Reuter C, Leverkus F. Frequency of idiopathic gastric stasis and intestinal transit disorders in essential dyspepsia. $\mathcal{F}$ Clin Gastroenterol 1989 11: $163-8$.

6 Rees WDW, Miller LJ, Malagelada J-R. Dyspepsia, antral motor dysfunction, and gastric stasis of solids. Gastroenterology $1980 ; 78: 360-5$.

7 You CH, Lee KY, Chey WY, Menguy R. Electrogastrographic study of patients with unexplained nausea, bloating and vomiting. Gastroenterology 1980; 79: 311-4.

8 Bortolotti M, Sarti P, Barbara L, Brunelli F. Gastric myoelectric activity in patients with chronic idiopathic gastroelectric activity in patients with chronic idiopathic gastro-

9 Talley NJ, Shuter B, McCrudden G, Jones M, Hoschl R, Piper $\mathrm{DW}$. Lack of association between gastric emptying of solids and symptoms in non-ulcer dyspepsia. F Clin Gastroentero 1989; 11: 625-30.

10 Read NW, Houghton LA. Physiology of gastric emptying and pathophysiology of gastroparesis. Gastroenterol Clin North Am 1989; 18: 359-73.

11 Barker MCJ, Cobden I, Axon ATR. Proximal stomach and antrum in stomach emptying. Gut 1979; 20: 309-11.

12 Sheiner HJ, Quinlan MF, Thompson IJ. Gastric motility and emptying in normal and post-vagotomy subjects. Gut 1980 21:753-9.

13 Collins PJ, Horowitz M, Chatterton BE. Proximal, distal and total stomach emptying of a digestible solid meal in normal subjects. B R Radiol 1988; 61: 12-8.

14 Houghton LA, Mangall YF, Read NW. Effect of incorporating fat into a liquid test meal on the relation between intragastric distribution and gastric emptying in human volunteers. Gut 1990; 31: 1226-9.

15 Collins PJ, Houghton JA, Read NW, Horowitz M, Chatterton $\mathrm{BE}$, Heddle R, et al. Role of the proximal and distal stomach in mixed solid and liquid meal emptying. Gut 1991; 32 $615-9$.

16 Tothill P, McLoughlin GP, Heading RC. Techniques and errors in scintigraphic measurements of gastric emptying. 7 Nucl Med 1978; 19: 256-61.

17 Siegel S. Non-parametric statistics for the behavioural sciences. New York: McGraw Hill, 1956.

18 Kelly K. Gastric emptying of liquids and solids: roles of proximal and distal stomach. Am $\mathcal{f}$ Physiol 1980; 239: G71-6.

19 Jobin G, Jian R. Isotope studies in gastric emptying. Dig Dis Sci 1982; 27: 571 .

20 Minami H, McCallum RW. The physiology and pathophysiology of gastric emptying in humans. Gastroenterology 984; 86: 1592-610.

21 Ricci R, Bontempo I, La Bella A, De Tschudy A, Corazziari E. Dyspeptic symptoms and gastric antrum distribution. An ultrasonographic study. Ital $f$ Gastroenterol 1987; 19 . 215-7.

22 Bradette M, Pare P, Douville P, Morin A. Visceral perceptio in health and functional dyspepsia: Crossover study of gastric distension with placebo and domperidone. Dig Dis Sci 1991; 36: 52-8.

23 Lehmann A, Dederding JP, Flourie B, Franchisseur C Rambaud JC, Jian R. Abnormal perception of visceral pain in response to gastric distension in chronic idiopathic dyspepsia. Dig Dis Sci 1991; 36: 1249-54.

24 Mearin F, Cucola M, Azpiroz F, Malagelada J-R. The origin of symptoms on the brain-gut axis in functional dyspepsia. Gastroenterology 1991; 101: 999-1006. 
25 Troncon LEA, Thompson DG, Ahluwalia NK, Barlow J, Heggie LJ. Abnormalities of intragastric pressure-volume
relationship and visceral perception in functional dyspepsia. relationship and visceral per

26 Camilleri M, Malagelada J-R, Kao PC, Zinsmeiter AR. Gastric and autonomic responses to stress in functional dyspepsia. Dig Dis Sci 1986; 31: 1169-77.

27 Malagelada J-R, Stanghellini V. Manometric evaluation of functional upper gut symptoms. Gastroeneterology 1985; 88: 1223-31.
28 Azpiroz F, Malagelada J-R. Perception and reflex relaxation of the stomach in response to gut distension. Gastroenterology

29 Hausken T, Berstadt A. Wide gastric antrum in patients with non-ulcer dyspepsia. Effect of cisapride. Scand $\mathcal{F}$

30 Jones RH, Lydeard SE, Hobbs FDR, Kenkre JE, Williams EI, Jones SJ, et al. Dyspepsia in England and Scotland. Gut 1990; 31: 401-5. 